evaluating safety in oral contraception, and as was shown by the belief that masturbation caused insanity. The dangers of addiction and HIV infection are both so great that we should, as a profession, try to get the right response and carry society with us.

R. F. HILL

Wonford House Hospital

Dryden Road

Wonford

Exeter EX2 5AF

\section{Children surviving parental murder}

SIR: We agree with Black \& Kaplan (Journal, November 1988, 153, 624-631) that children surviving after the father has killed the mother should not automatically be placed with relatives, and that a child psychiatric team has an important role in the intervention following such tragedies. We have been involved in two cases recently which highlight Black \& Kaplan's recommendations.

Case Report (i): A 12-year-old girl presented with multiple tics and vocal utterances a few months after starting secondary school. Her father had killed her mother when she was an infant, and she had been placed with her maternal grand parents, whom she had come to know as "Mummy and Daddy". They had taken her regularly, through her primary school years, to the grave of "Mummy Gloria", but had never told her who this was or what had happened. They completely refused to talk about her father, and her paternal grandparents had been totally excluded from contact with her before she had reached the age of 2 . They refused to allow the girl to be seen by her father in prison. When the girl was 8 years old they were seen by a child psychiatrist, at the request of social services, regarding the advisability of access to her father. They refused to talk to the girl about her father, wanting to put off such discussion till she was older. In the face of the opposition to him, the father eventually gave up trying to make contact with the girl. In her first few months at secondary school she mixed with peers from the wider community, some of whom had passed remarks to her about her father having killed her mother. Shortly after this, her symptoms led to her referral to us. Despite various treatment approaches, her symptoms have run a fluctuating course, and her grandparents have persistently avoided all attempts to talk openly, either individually or in family sessions, about the circumstances of her mother's death. The girl's education has been considerably disrupted due to handicapping symptoms.

Case Report (ii): Three children, aged 4, 7, and 9, were referred to us by a social worker, along with three sets of maternal aunts and uncles with whom they had been placed following the killing of their mother by their acutely psychotic father. The social worker wanted counselling for the children and for the aunts and uncles, who already were non-verbally giving the message to the children that talk of the father was taboo. Joint interviews were held on a number of occasions with all three sets of relatives to discuss their loss of their sister, their feelings towards her husband, who was in a special hospital, and how the children's needs to grieve their mother and retain a positive perception of their father could be best met. There were also persisting fears regarding the short lived nature of the father's psychiatric illness and the possibility that his children might one day pose a similar threat to their own children. The children were seen individually and as a group. As their respective foster families all lived within a short distance of each other, and as they still attended the same school, their sense of identity as siblings was being maintained. Each was also a member of another family. They knew what father had done and had found a way of coping with it - he had "gone out into the cold without his cap on and had got a cold in his head". He was thus ill when he had killed their mother. All three families were helped to mark the anniversary of the tragedy by a visit to mother's grave for a shared placing of flowers.

In case (i) the psychological stresses of being placed with maternal grandparents who failed to resolve their grief and anger have probably contributed heavily to the development of a Gilles de la Tourette syndrome. In case (ii), intervention at an early stage after placement with maternal relatives will hopefully facilitate a better outcome.

NoEl McCune Patricia Donnelly

The Department of Child Psychiatry The Royal Belfast Hospital for Sick Children Belfast BT12 6BE

\section{Capgras' syndrome and town duplication}

SIR: Anderson (Journal, November 1988, 153, 694699) concludes that the Capgras phenomenon is not specific for people, but includes a range of objects of importance in the patient's life. Traditionally, the Capgras phenomenon was said to be a delusional misinterpretation of people enjoying a close personal relationship, most often the spouse, and this could be explained in psychodynamic terms by ambivalence on the part of the patient towards the person who has been duplicated. We describe a case in which the affective bond to the inanimate object is totally absent.

Case Report: Mr E. was a 32-year-old fireman, who presented to the casualty department complaining that the town in which he lived had been duplicated "somewhere in Asia". He had no previous psychiatric history. On the night in question, he presented unkempt and unshaven, in a high state of arousal. His speech was pressured and he described his thoughts as "crashing over each other". He said he had 
taken amphetamines. He claimed that the whole of the town in which he lived had been duplicated in Asia by his drug dealers because he would not co-operate with them. He knew the town was not the real one, because not only did it not seem "quite right", but because many of the cars only had one person in them, which confirmed his suspicions. He was amazed that they should go to all this trouble for him and believed they must have drugged him to take him there, as he had no memory of the journey. Interestingly, neither his wife nor family had been duplicated, despite being implicated in the plot.

He had neither visual nor auditory hallucinations. Despite his inability to concentrate, he was orientated in time, place, and person. Physical examination found him sweating, with a tachycardia. His pupils were dilated, but there were no focal signs. He was admitted to the ward and given chlorpromazine, but absconded early the following morning.

At follow-up, he remembered his experiences and ascribed them to a particularly 'bad' batch of amphetamines which he had recently purchased.

The specificity of Capgras' syndrome for people was soon found to be illusory (Coleman, 1933), when the phenomenon was described in relation to inanimate objects (in Coleman's case, letters). The psychodynamic argument was thus widened to suggest that ambivalence could also be expressed towards such objects that were affectively important to the patient. It is hard to see how the duplication of a large tract of south-east London could be explained along such psychodynamic lines.
Amphetamines are known to cause alterations in brain biochemistry and to produce states indistinguishable from schizophrenia or mania (Connell, 1958), despite which the Capgras phenomenon does not appear to have been previously described in such a situation. This case appears in the setting of amphetamine intoxication and, hence, has an underlying organic basis which further disproves a psychodynamic interpretation.

The only two previous reports of duplication of cities (Thompson et al, 1980; Kiriakos et al, 1980) have, unfortunately, made little attempt to interpret the findings in either a psychodynamic or organic fashion.

We would like to thank Dr R. Proud for allowing us to report on her patient.

Christopher Ball TIM EXWORTHY

York Clinic

Guy's Hospital

London SE1 9RT

\section{References}

Coleman, S. M. (1933) Misidentification and non-recognition. Journal of Mental Science, 79, 42-51.

Connell, P. H. (1958) Amphetamine Psychosis. Maudsley Monograph No. 5. London: The Maudsley Hospital.

KIRIAKOS, R. et al (1980) Review of 13 cases of Capgras' syndrome. American Journal of Psychiatry, 137, 1605-1607.

Thompson, M. Z. et al (1980) Misidentification of a city. I. Delimiting the criteria for Capgras' syndrome. American Journal of Psychiatry, 137, 1270-1271.

\section{A HUNDRED YEARS AGO}

\section{Insomnia}

In spite of all the criticisms to which the modern art of medicine is so frequently subjected by our literary friends, few pictures indicate a fuller grasp of the requirements of medicinal treatment than that given by our greatest dramatist. The aim of modern therapeutics is directed more and more to the employment of measures by which a return to the normal state can be attained, when in presence of disease nothing better can be desired than the elimination of all those abnormal features by which the sick person differs from his original healthy condition. The revival at the Lyceum serves to recall that Macbeth's contemptuous "Throw physic to the dogs" really forms one long exposition of the limitations of the use of drugs and of the conviction of the efficacy of the natural methods of cure. The number of references made throughout the play to sleep and dreams is remarkable. In turn, the theme is taken up until sleep is eulogised as "balm of hurt minds, great Nature's second course, chief nourisher in life's feast", and from this point attention is concentrated upon the results of sleepiness, or of sleep perturbed by frightful visions, until it culminates with the sleep-walking scene of Lady Macbeth, and "the thick-coming fancies that keep her from her rest", and her probable suicide. No medical man can sit through this performance without wishing that he had been called during the early stages of the malady. On all hands the underlying cause is recognised, and the proper method of treatment is clearly indicated. Science was in its infancy, however, or we should have been deprived of the pleasure of this portrayal of an interesting medical and psychological study.

The Lancet, 5 January 1889.

\section{Researched by Henry Rollin, Emeritus Consultant Psychiatrist, Horton Hospital, Surrey}

